\title{
Study of The Relationship between Severity of Liver Cirrhosis and Pulmonary Function Tests
}

Nabil Farouk Awad ${ }^{1}$, Abd-Allah Mohammad Elbalsha', Mohamed Zakria Abo Amer ${ }^{2}$, Mohamed Helmy Elsayed Ibrahim ${ }^{1 *}$

Departments of Chest Diseases ${ }^{1}$ and Tropical Medicine ${ }^{2}$, Faculty of Medicine, Al-Azhar University *Corresponding author: Mohamed Helmy Elsayed Ibrahim, Mobile: (+20) 01552935770,

Email: mohamedhelmy111992@gmail.com

\section{ABSTRACT}

Background: Cirrhosis is a condition in which the liver does not function properly due to long-term damage. This damage is characterized by the replacement of normal liver tissue by scar tissue.

Objective: The aim of this work is to study the relationship between severity of liver cirrhosis according to the ChildPugh score and pulmonary function tests (namely spirometry and arterial blood gas).

Patients and Methods: The study is a cross sectional one, which was carried out on 50 patients admitted in the inpatient wards, or in regular follow-up in the out-patient's clinics of the Gastroenterology Departments, in Al-Azhar University Hospitals between November 2018 and May 2019. They were divided into 3 groups according to Child Pugh Classification (A, B and C).

Result: The prevalence of hypoxia was (30\%) in all studied groups (50 patients), the hypoxia was present in patients with Child $\mathrm{C}$ and Child B (62\%) and (29.4\%) respectively but none of Child A had hypoxia. It was noted that all pulmonary functions were worst in patients Child class $\mathrm{C}$ when compared to other groups. However, patients Child B had also significantly worse pulmonary functions when compared to patients class A. We also showed that pulmonary functions are significantly correlated with synthetic liver function, Child and MELD score. The deterioration of liver functions and rise of patients score is accompanied by worsening of all pulmonary functions.

Conclusion: Patients suffering from severe liver cirrhosis and ascites, have significant reduction in $\left(\mathrm{PaO}_{2}\right)$ and $\left(\mathrm{SaO}_{2}\right)$ in association with restrictive pulmonary function pattern (up to 100\% of patients with massive ascites).

Keywords: Liver Cirrhosis, Pulmonary Function Tests, Child Pugh Classification.

\section{INTRODUCTION}

The severity of cirrhosis is commonly classified with the Child-Pugh score. This scoring system uses bilirubin, albumin, INR, the presence and severity of ascites and encephalopathy to classify patients into class A, B or C. Class A has a favorable prognosis, while class $\mathrm{C}$ is at high risk of death. This system was devised in 1964 by Child and Turcotte, and modified in 1973 by Pugh and others ${ }^{(\mathbf{1})}$.

Pulmonary complications such as hepatopulmonary syndrome, porto-pulmonary hypertension , hepatic hydrothorax and spontaneous bacterial empyema are observed frequently in these patients ${ }^{(2)}$. Pulmonary function tests (PFTs) are an important tool in the investigation and monitoring of patients with respiratory pathology. They provide important information relating to the large and small airways, the pulmonary parenchyma and the size and integrity of the pulmonary capillary bed. Although they do not provide a diagnosis per se, different patterns of abnormalities are seen in various respiratory diseases which helps to establish a diagnosis ${ }^{(3)}$.

Liver cirrhosis is often accompanied by arterial hypoxemia in the absence of cardiopulmonary disease $^{(4)}$.

In addition, abnormalities in pulmonary function and impaired gas exchange may occur in as many as 45$50 \%$ of patients ${ }^{(5)}$. Certain pulmonary functions may be impaired in chronic liver disease. In general, a reduction in total lung capacity, airway obstruction, impairment in diffusion capacity, and restrictive types of abnormalities such as increase in the alveolararterial oxygen difference are manifested ${ }^{\left({ }^{(6)}\right.}$.

\section{AIM OF THE STUDY}

The aim of this work is to study the relationship between severity of liver cirrhosis according to the Child-Pugh score and pulmonary function tests (namely spirometry and arterial blood gas).

\section{PATIENTS AND METHODS}

The study is a cross sectional one, was carried out on 50 patients admitted in the inpatient wards, or in regular follow-up in the out-patient's clinics of the Gastroenterology departments, in Al-Azhar University Hospitals between November 2018 and May 2019.

\section{Clinical work up:} Patients:

The study included 50 patients with liver cirrhosis 16 males and 34 females, in our study. The mean age of the patients was $47.5 \pm 17.2$ years. The patients will be recruited from outpatient clinic (and/or) inpatient department consecutively and divided into 3 groups according to Child Pugh Classification.

- Group (I) Child A: 17 patients with liver cirrhosis (child pugh score <7)

- Group (II) Child B: 17 patients with liver cirrhosis (child pugh score 7-9)

- Group (III) Child c: 16 patients with liver cirrhosis (child pugh score 10-15)

The mean age of the patients was $38.6 \pm$ 13.1years, $49.6 \pm 12.9$ years, $48.6 \pm 5.0$ years in groups I, II, III respectively. 
Ethical approval and written informed consent:

The study explained to all participants before inclusion and a written consent was taken from each one included in the study and approved by medical ethical committee in hospitals.

Inclusion criteria:

- Patients with liver cirrhosis.

- Non-smokers.

Exclusion criteria:

- Patients with very poor general state.

- Patients having lung and/or heart diseases.

- Patients with medical conditions that may cause impairment of their pulmonary function tests, or lead to hypoxemia, such as: morbid obesity, neuromuscular disorders, severe deformities of chest wall or vertebral column ....etc.

Patients were subjected to the following:

(1) Full history taking:

(2) Clinical examinations:

(3) Laboratory investigations:

(4) Chest X -ray and Electrocardiography.

To exclude chest and heart diseases.

Echocardiogram was done in some patients.

(5) Abdominal ultrasonography to determine:

- $\quad$ presence of liver cirrhosis.

- $\quad$ presence or absence of ascites.

- absence of focal lesion in the liver.

For all participants three groups of pulmonary function tests will be done:

(a) Arterial blood gases (ABG):

The arterial blood gases were done using Radiometer Medical APS, DK-2700.

Precautions:

- The samples were taken while the patients in recumbent position and breathing room air. Sample was taken from the radial artery of the non-dominant arm.

- Blood sample was drowning on Heparinized syringe using $0.5 \mathrm{ml}$ of heparin (1000units $/ \mathrm{ml}$ ).

\section{Measurements of ABG include:}

$\mathrm{pH}$, partial pressure of oxygen in arterial blood ( $\mathrm{PaO} 2)$, Oxygen saturation $(\mathrm{SaO} 2)$, and partial pressure of carbon dioxide ( $\mathrm{PCO} 2)$ normal value 35 to $45 \mathrm{mmHg}$. Patients with $\mathrm{PaO} 2$ values less than 80 $\mathrm{mmHg}$ were considered hypoxemic.

(b) Ventilation test (Spirometry):

Steps of the test:

1) Identification data of the subject were entered including his name, age, sex, and height to calculate the predicted values from equations that have been established as guidelines for normal subjects.

2) The test performed while the patients in setting position using the forced vital capacity maneuver, patients first took a deep breath and then took the mouthpiece in between their lips and made as forced and fast expiration as they could until their lungs were completely emptied. These maneuvers were performed three times by the patients and the highest values were chosen.

These values measured in liters per second or percentage from predicted values.

3) Measurements of Forced vital capacity (FVC), forced expiratory volume in the first second (FEV1), expiratory air flow rates in the middle segment (25-75\%) of FVC, and FEV1/FVC ratio were performed. FVC is the maximum volume of air that can be expired during forced expiration. It is $>80 \%$ of the predicted value by age, height, weight, and gender in normal lung. FEV1 is the amount of air that is exhaled in the first second during the forced vital capacity maneuver. In normal lung, it is $>80 \%$ of the predicted value.

The FEV1/FVC ratio is generally expressed as a percentage and in normal adult the ratio more than $70 \%$.

FEF $25-75 \%$ is the rate of flow in the middle of the forced vital capacity maneuver if below 65\% indicates small airway diseases or poor effort.

4) Restrictive ventilatory disorder was determined on the basis of spirometric parameters: $\mathrm{FEV}_{1} / \mathrm{FVC}$ ratio normal or increased, FVC marked decreased and FEV1decreased but not marked.

5) Obstructive ventilatory disorder was determined on the basis of the following: $\mathrm{FEV}_{1} / \mathrm{FVC}$ ratio Values below $70 \%$ and FEV1 show marked decreased.

\section{Statistical analysis:}

Recorded data were analyzed using the statistical package for social sciences, version 20.0 (SPSS Inc., Chicago, Illinois, USA). Quantitative data were expressed as mean \pm standard deviation (SD). Qualitative data were expressed as frequency and percentage.

\section{The following tests were done:}

- Independent-samples t-test of significance was used when comparing between two means.

- Chi-square $\left(\mathrm{x}^{2}\right)$ test of significance was used in order to compare proportions between two qualitative parameters.

- The confidence interval was set to $95 \%$ and the margin of error accepted was set to $5 \%$. The p-value was considered significant as the following:

- Probability (P-value)

- P-value $<0.05$ was considered significant.

- P-value $<0.001$ was considered as highly significant.

- P-value >0.05 was considered insignificant.

\section{RESULTS}

The present study included 50 cirrhotic patients selected from the inpatient wards, or in regular followup in the out-patient's clinics of the Gastroenterology departments, in Al- Azhar University Hospitals. They were 17 patients group I (Child A), 17 patients group II (Child B) and 16 patients group III (Child C). 
Table (1): Comparison between studied groups as regard demographic data.

\begin{tabular}{|c|c|c|c|c|c|}
\hline \multicolumn{2}{|l|}{ Variables } & $\begin{array}{l}\text { Group I } \\
(\mathbf{N}=17)\end{array}$ & $\begin{array}{c}\text { Group II } \\
(\mathbf{N}=17)\end{array}$ & $\begin{array}{c}\text { Group III } \\
(\mathbf{N}=\mathbf{1 6})\end{array}$ & P-value \\
\hline Age (years) & $\begin{array}{c}\text { Mean } \\
+ \text { SD }\end{array}$ & $\begin{array}{l}38.6 \\
131\end{array}$ & $\begin{array}{l}49.6 \\
129\end{array}$ & $\begin{array}{l}48.6 \\
5001\end{array}$ & $0.011 * *$ \\
\hline Sex & $\begin{array}{c}\text { Males } \\
\text { Females }\end{array}$ & $\begin{array}{c}6(35.3 \%) \\
11(64.7 \%)\end{array}$ & $\begin{array}{l}8(47 \%) \\
9(53 \%)\end{array}$ & $\begin{array}{c}2(12.5 \%) \\
14(87.5 \%)\end{array}$ & 0.098 \\
\hline
\end{tabular}

**: p-value $<0.05$ is considered significant.

This table shows:

- Statistically significant difference (p-value $<\mathbf{0 . 0 5}$ ) between studied groups as regard age.

- No statistical significant difference (p-value $>\mathbf{0 . 0 5}$ ) between studied groups as regard sex.

The study includes 50 patients with liver cirrhosis. The age of the patients ranged from 18-60 years. There were 34 females (68\%) and 16 males (32\%).

* Group (I): Includes 11 females $(64.7 \%)$ and 6 males (35.3\%) with mean age 38.6 \pm 13.1 years.

* Group (II): Includes 9 females (53\%) and 8 males (47\%) with mean age 49.6 \pm 12.9 years.

* Group (III): Includes 14 females (87.5\%) and 2 males (12.5\%) with mean age $48.6 \pm 5.001$ years.

Table (2): Classification of studied patients as regard CHILD score.

\begin{tabular}{|c|c||c|c|c|c|}
\hline \hline \multicolumn{2}{|c|}{ Variables } & $\begin{array}{c}\text { Group I } \\
(\mathbf{N = 1 7 )}\end{array}$ & $\begin{array}{c}\text { Group II } \\
(\mathbf{N}=\mathbf{1 7})\end{array}$ & $\begin{array}{c}\text { Group III } \\
(\mathbf{N}=\mathbf{1 6})\end{array}$ & p-value \\
\hline \multirow{2}{*}{ Child score } & Mean & 5.8 & 7.8 & 12.1 & $<$ \\
\cline { 2 - 6 } & $\mathbf{\pm S D}$ & 0.4 & 1.03 & 1.3 & $<\mathbf{0 . 0 0 1}^{*}$ \\
\hline
\end{tabular}

*: p-value $<0.001$ is considered highly significant.

Child score.

This table shows highly statistically significant difference (p-value $<\mathbf{0 . 0 0 1})$ between studied groups as regard

Table (3): Comparison between studied groups as regard MELD score.

\begin{tabular}{|c|c|c|c|c||c||}
\hline \multirow{2}{*}{ Variables } & $\begin{array}{c}\text { Group I } \\
(\mathbf{N = 1 7 )}\end{array}$ & $\begin{array}{c}\text { Group II } \\
(\mathbf{N = 1 7 )}\end{array}$ & $\begin{array}{c}\text { Group III } \\
(\mathbf{N = 1 6 )}\end{array}$ & P-value \\
\hline \multirow{2}{*}{ MELD score } & Mean & 7.3 & 11.0 & 16.0 & $<\mathbf{0 . 0 0 1}^{*}$ \\
\cline { 2 - 6 } & $\mathbf{\pm S D}$ & 0.9 & 0.8 & 1.6 & $<$ \\
\hline
\end{tabular}

*: p-value $<0.001$ is considered highly significant.

This table shows highly statistical significant difference $(\mathbf{p}$-value $<\mathbf{0 . 0 0 1})$ between studied groups regarding to MELD score.

Table (4): Comparison between different groups as regard complications.

\begin{tabular}{|c|c|c|c|c|c|}
\hline \multicolumn{2}{|l|}{ Variables } & $\begin{array}{l}\text { Group I } \\
(\mathbf{N}=17)\end{array}$ & $\begin{array}{l}\text { Group II } \\
(\mathbf{N}=17)\end{array}$ & $\begin{array}{l}\text { Group III } \\
(\mathbf{N}=16)\end{array}$ & P-value \\
\hline \multirow{2}{*}{ Clubbing } & No & $17(100 \%)$ & $14(82.4 \%)$ & $11(68.75 \%)$ & \multirow{2}{*}{0.088} \\
\hline & Yes & $0(0 \%)$ & $3(17.6 \%)$ & $5(31.25 \%)$ & \\
\hline \multirow{2}{*}{ Cyanosis } & No & $17(100 \%)$ & $14(82.4 \%)$ & $13(75 \%)$ & \multirow{2}{*}{0.159} \\
\hline & Yes & $0(0 \%)$ & $3(17.6 \%)$ & $3(25 \%)$ & \\
\hline \multirow{2}{*}{ Dyspnea } & No & $17(100 \%)$ & $8(47.1 \%)$ & $4(25 \%)$ & \multirow{2}{*}{$<0.001 *$} \\
\hline & Yes & $0(0 \%)$ & $9(52.9 \%)$ & $12(75 \%)$ & \\
\hline \multirow{2}{*}{ Bleeding OV } & No & $17(100 \%)$ & $7(41.2 \%)$ & $0(0 \%)$ & \multirow{2}{*}{$<0.001 *$} \\
\hline & Yes & $0(0 \%)$ & $10(58.8 \%)$ & $16(100 \%)$ & \\
\hline \multirow{2}{*}{ Splenomegaly } & No & $17(100 \%)$ & $3(17.6 \%)$ & $0(0 \%)$ & \multirow{2}{*}{$<0.001 *$} \\
\hline & Yes & $0(0 \%)$ & $14(82.4 \%)$ & $16(100 \%)$ & \\
\hline
\end{tabular}

*: p-value $<0.001$ is considered highly significant.

This table shows:

- Highly statistically significant difference (p-value $<\mathbf{0 . 0 0 1}$ ) between studied groups as regard dyspnea, bleeding OV (esophageal varices) and splenomegaly.

- No statistically significant difference (p-value $>\mathbf{0 . 0 5}$ ) between studied groups as regard clubbing and cyanosis. 
Table (5): Comparison between studied groups as regard liver function tests.

\begin{tabular}{|c|c|c|c|c|c|}
\hline Variables & Group & $\begin{array}{l}\text { Group I } \\
(\mathbf{N}=17)\end{array}$ & $\begin{array}{l}\text { Group II } \\
(\mathbf{N}=17)\end{array}$ & $\begin{array}{c}\text { Group III } \\
(\mathbf{N}=16)\end{array}$ & P-value \\
\hline \multirow{2}{*}{ ALT (U/L) } & Mean & 37.5 & 37.1 & 48.8 & \multirow{2}{*}{$0.021 * *$} \\
\hline & $\pm \mathrm{SD}$ & 8.6 & 1.8 & 7.9 & \\
\hline \multirow{2}{*}{ AST (U/L) } & Mean & 50.1 & 50.5 & 53.9 & \multirow{2}{*}{0.63} \\
\hline & \pm SD & 10.9 & 12.9 & 12.6 & \\
\hline \multirow{2}{*}{ ALB (mg/dl) } & Mean & 3.4 & 2.7 & 1.9 & \multirow{2}{*}{$<0.001 *$} \\
\hline & \pm SD & 0.2 & 0.2 & 0.2 & \\
\hline \multirow{2}{*}{$\begin{array}{l}\text { T.bilirubin } \\
\text { (mg/dl) }\end{array}$} & Mean & 1.2 & 1.9 & 4.5 & \multirow{2}{*}{$<0.001 *$} \\
\hline & \pm SD & 0.2 & 0.05 & 0.8 & \\
\hline \multirow{2}{*}{ PT (sec) } & Mean & 13.2 & 17.1 & 25.1 & \multirow{2}{*}{$<0.001 *$} \\
\hline & \pm SD & 1.3 & 2.01 & 1.7 & \\
\hline \multirow{2}{*}{ INR } & Mean & 1.2 & 1.6 & 2.3 & \multirow{2}{*}{$<0.001 *$} \\
\hline & \pm SD & 0.1 & 0.2 & 0.3 & \\
\hline
\end{tabular}

$* *$ : p-value $<0.05$ is considered significant, $*$ : p-value $<0.001$ is considered highly significant.

This table shows:

- No statistically significant difference (p-value $>\mathbf{0 . 0 5}$ ) between studied groups as regard AST.

- Statistically significant difference $(\mathbf{p}$-value $<\mathbf{0 . 0 5})$ between studied groups as regard ALT.

- Highly statistically significant difference (p-value $<0.001$ ) between studied groups as regard ALB, Total bilirubin, PT and INR.

Table (6): Correlation between severity of liver cirrhosis (CHILD score) and (ABG \& PFTs) in group I.

\begin{tabular}{|c|c|c|}
\hline $\begin{array}{lc}\text { Variables } & \text { Group I } \\
\end{array}$ & $(\mathbf{r})$ & p-value \\
\hline CHILD score vs pH & -0.4 & 0.1 \\
\hline CHILD score vs PCO2 & 0.2 & 0.53 \\
\hline CHILD score vs PO2 & -0.3 & 0.24 \\
\hline CHILD score vs Sat O2 & -0.4 & 0.13 \\
\hline CHILD score vs FVC & -0.06 & 0.79 \\
\hline CHILD score vs FEV1 & -0.3 & 0.32 \\
\hline CHILD score vs FEV1/FVC & -0.51 & $0.035 * *$ \\
\hline CHILD score vs FEF $(25-75 \%)$ & -0.47 & 0.053 \\
\hline
\end{tabular}

(r): Pearson correlation coefficient, $* *$ : p-value $<0.05$ is considered significant.

This table shows:

- Statistically significant ( $\mathbf{p}$-value $<\mathbf{0 . 0 5})$ Negative correlation $(\mathbf{r}=\mathbf{- 0 . 5 1})$ between severity of liver cirrhosis (CHILD score) and FEV1/FVC in group I.

- No statistical significant (p-value $>\mathbf{0 . 0 5}$ ) correlation between severity of liver cirrhosis (CHILD score) and (ABG \& PFTs) in group I.

Table (7): Correlation between severity of liver cirrhosis (CHILD score) and (ABG \& PFTs) in group II.

\begin{tabular}{|c|c|c|}
\hline $\begin{array}{ll}\text { Variables } & \text { Group II }\end{array}$ & (r) & p-value \\
\hline CHILD score vs pH & 0.3 & 0.29 \\
\hline CHILD score vs PCO2 & -0.3 & 0.29 \\
\hline CHILD score vs PO2 & -0.3 & 0.12 \\
\hline CHILD score vs Sat O2 & -0.2 & 0.36 \\
\hline CHILD score vs FVC & 0.6 & $0.016 * *$ \\
\hline CHILD score vs FEV1 & -0.4 & 0.16 \\
\hline CHILD score vs FEV1/FVC & -0.4 & 0.15 \\
\hline CHILD score vs FEF (25 - 75\%) & -0.03 & 0.91 \\
\hline
\end{tabular}

(r): Pearson correlation coefficient, $* *$ : p-value $<0.05$ is considered significant.

This table shows:

- Statistically significant (p-value $<\mathbf{0 . 0 5}$ ) Positive correlation $(\mathbf{r}=\mathbf{0 . 6})$ between severity of liver cirrhosis (CHILD score) and FVC in group II. No statistically significant (p-value $>\mathbf{0 . 0 5}$ ) correlation between severity of liver cirrhosis (CHILD score) and (ABG \& PFTs) in group II. 
Table (8): Correlation between severity of liver cirrhosis (CHILD score) and (ABG \& PFTs) in group III.

\begin{tabular}{|c|c|c|}
\hline $\begin{array}{ll}\text { Variables } & \text { Group III } \\
\end{array}$ & (r) & p-value \\
\hline CHILD score vs pH & -0.09 & 0.74 \\
\hline CHILD score vs PCO2 & -0.3 & 0.32 \\
\hline CHILD score vs PO2 & -0.04 & 0.88 \\
\hline CHILD score vs Sat $\mathrm{O2}$ & -0.07 & 0.78 \\
\hline CHILD score vs FVC & -0.2 & 0.4 \\
\hline CHILD score vs FEV1 & 0.2 & 0.56 \\
\hline CHILD score vs FEV1/FVC & -0.004 & 0.98 \\
\hline CHILD score vs FEF (25 - 75\%) & 0.3 & 0.34 \\
\hline
\end{tabular}

(r): Pearson correlation coefficient.

This table shows no statistically significant (p-value $>\mathbf{0 . 0 5}$ ) correlation between severity of liver cirrhosis (CHILD score) and (ABG \& PFTs) in group III.

\section{DISCUSSION}

In the current study 50 cirrhotic patients were evaluated regarding the arterial blood gases analysis, spirometry. The patients were divided into 3 groups, group I (Child A) 17 patients, group II (Child B) 17 patients, and group III (Child C) 16 patients. All enrolled patients had liver cirrhosis 2 ry to chronic hepatitis $\mathrm{C}$ virus.

(I) The results of (ABG) arterial blood gases revealed that:

The mean partial arterial carbon dioxide pressure $\left(\mathrm{PCO}_{2}\right)$ in group III (Child C) was significantly lower when compared to group I (Child A) and group II (Child B) (Table 8).

Partial arterial oxygen pressure $\left(\mathrm{Pa} \mathrm{O}_{2}\right)$ is considered low if the value less than $80 \mathrm{mmHg}$ in arterial blood. Among the studied population, there were 15 patients (30\%) had hypoxia (Table 8). None of them was in group (I), 5 patients were in group (II) (29.4\%) and 10 patients $(62.6 \%)$ had hypoxia were in group (III). The difference in mean $\left(\mathrm{Pa} \mathrm{O}_{2}\right)$ value between the different groups was significant.

Further analysis showed that hypoxia occurred significantly in patients with ascites group (II) \& group (III) compared to those without ascites group (I) as none of them had hypoxia.

So, with progression of liver disease hypoxemia become more frequent, presence of ascites and its progressive increase in amount can explain such observation (mechanical effect). However, it may be also related to presence of portopulmonary shunts so blood escape oxygenation.

Oxygen Saturation $\left(\mathrm{SaO}_{2} \%\right)$ in Group (III) showed significantly lower mean value when compared to group (I) and group (II). Again, patients with ascites showed highly significant lower Oxygen Saturation when compared to patients without ascites.

The results of our study agreed with Medha $\boldsymbol{e t}$ al. ${ }^{(7)}$, who studied arterial hypoxemia in patients with liver cirrhosis that revealed decrease arterial oxygen tension and oxygen saturation in patients with chronic liver disease and cirrhosis.

In another study done by Konstantinos et al. ${ }^{(8)}$, they found that; reduction of $\mathrm{Pa} \mathrm{O}_{2}$ and $\mathrm{Sa}_{2}$ directly correlated with advanced liver cirrhosis and increased grade of ascites.

Irem et al. ${ }^{(9)}$, also studied the relation between liver cirrhosis and pulmonary function tests on 39 patients. They found that; the values of $\mathrm{Pa}_{2}$ and $\mathrm{Sa} \mathrm{O}_{2}$ were lower in patients with ascites when compared to patients without ascites, and $33.3 \%$ of patients had hypoxia. In their study, there were no statistical significance difference between number of patients who had hypoxia in child $\mathrm{B}$ and $\mathrm{C}$ patients.

Chang et al. ${ }^{(10)}$, published a study in which they explored the effect of ascites on pulmonary functions in two groups of patients, they compared the therapeutic effects of paracentesis and diuretics on $\mathrm{P}_{\mathrm{a}} \mathrm{O}_{2}$. They found that; On the contrary to the patients managed by paracentesis, those treated with diuretics manifested significant improvement of gas exchange, along with $\mathrm{P}_{\mathrm{a}} \mathrm{O}_{2}$ increase and pulmonary function improvement. This suggests that; beside mechanical effect of ascites, the interstitial pulmonary edema and fluid retention contribute additionally to gas exchange impairment.

(II) The results of spirometry revealed that:

The results of our study as regard spirometry in all patients revealed that: Forced Vital Capacity $(\mathrm{FVC})$ and Forced Expiratory Volume in $1^{\text {st }}$ second (FEV1), in the patients with group III (child C) were significantly lower when compared to group (I and II). Also Forced Expiratory Flow at 25\% to $75 \%$ forced vital capacity (FEF 25-75\%) showed a statistically significant difference when compared group (I) with group (II and III).

Analysis of spirometry results in cirrhotic patients with and without ascites in the present study showed that; FVC, FEV1, and FEF 25- 75\% were significantly lower in the patients with ascites when 
compared to patients without ascites, and significantly decreased with increasing the severity of ascites.

This observation was similar to the results obtained by Nagral et al. (11), which revealed that; pulmonary functions are impaired with cirrhosis and ascites which cause further deterioration. As in cirrhotic patients without ascites, FVC, TLC (total lung capacity), FEV1 were lower than predicted values. In patients with ascites, FVC, FEV1, FEF25-75\% were significantly lower as compared to predicted values. FVC, FEV1, FEF25- 75 decreased significantly with increasing amount of ascites.

A study was done in 2002 by Djordje $\boldsymbol{e t}$ al. ${ }^{(12)}$ and included a group of 18 non-smokers with liver cirrhosis. Ten patients were diagnosed to had lower transfer factor, reduced vital capacity (VC), decreased forced expiratory volume during the first second (FEV1), and forced expiratory flow at $25-75 \%$ forced vital capacity. This finding is explained by early, substantial changes or pulmonary parenchymal edema. Restrictive ventilatory disorders were diagnosed in 12 (38.7\%) patients with ascites. In comparison with group without ascites, significantly higher incidence of restrictive ventilatory disorders was found in patients with ascites.

Reduction of ascites leads to improvement of total pulmonary capacity, functional residual capacity, and airway flow. The best improvement was noted in the expiratory reserve volume ${ }^{(12)}$.

Restrictive ventilatory function is predominant in our patients. As 23 patients (46\%) of all patients had restrictive ventilation and 5 patients $(10 \%)$ had obstructive ventilatory function while 16 patients (32\%) had combined obstructive and restrictive ventilatory function. The obstructive ventilatory function is insignificant. Restrictive ventilatory function and combined obstructive as well as restrictive ventilatory function are common in group III $(8+6)(87.5 \%)$ than group II (5+9) $(82.3 \%)$ and group I $(10+1)(64 \%)$.

So, there was a trend of higher number of patients with restrictive and combined pulmonary functions pattern with higher grade of Child classification.

The results of the present study are in agreement with a study conducted by Hourani et al. ${ }^{(5)}$, where they studied pulmonary dysfunction in advanced liver disease. which revealed $25 \%$ of patients had ventilatory restriction, airflow obstruction in only 3\%. Diffusion abnormality was accompanied with restrictive ventilatory defect in 35\% of patients. FEF $25-75 \%$ was abnormally reduced in about $27 \%$ of patients. The study also revealed low prevalence of severe abnormalities in maximal static respiratory pressure and many factors other than respiratory muscle weakness like (pleural effusion, ascites or interstitial pulmonary abnormalities) were responsible for restriction ${ }^{(5)}$.

In the present study the prevalence of restrictive ventilatory functions were found to be $(58.8 \%)$ in patients without ascites. This might be explained with interstitial pulmonary disease that affect the lung parenchyma which result from chronic hepatitis $\mathrm{C}$ virus. As one of the extra hepatic manifestation of hepatitis $\mathrm{C}$ virus is interstitial pulmonary fibrosis and all our patients were positive for hepatitis C virus (100\%).

Finally, in our work we studied the correlation between liver function tests and pulmonary function tests in all patients and we found that:

Synthetic liver functions (Albumin, Bilirubin and INR) which are used in scoring systems (Child and or MELD score) have significant correlation with pulmonary functions. The worse the values of liver functions and higher scores of liver impairment are accompanied by significant deterioration in parameters of pulmonary functions.

So, there is evidence that pulmonary status and complications in patients with liver cirrhosis are underestimated. Objective evaluation of pulmonary function tests in patients with liver cirrhosis will show significant impairment in pulmonary functions which is significantly correlated with deterioration of liver status.

Such findings should be considered when evaluating patients with liver disease, especially those who may require surgical intervention. Patients with moderate to severe ascites may need therapeutic paracentesis frequently to improve their pulmonary functions especially before minor interventions.

\section{CONCLUSION}

In conclusion, patients suffering from severe liver cirrhosis and ascites, have significant reduction in $\left(\mathrm{Pa} \mathrm{O}_{2}\right)$ and $\left(\mathrm{Sa}_{2} \mathrm{O}_{2}\right)$ in association with restrictive pulmonary function pattern (up to $100 \%$ of patients with massive ascites).

As a result, pulmonary resistance is impaired, and patients are more liable to infection and adult respiratory distress syndrome. Thus, prognosis in those patients is poor based on both hepatic and pulmonary diseases.

\section{RECOMMENDATIONS}

1- Arterial blood gases should be routinely done for all patients with liver cirrhosis to detect hypoxia that may be an indicator of HPS.

2- Pulmonary function tests should be done for all patients with liver cirrhosis, and especially those who require surgery or candidate for liver transplantation in order to detect pulmonary complications.

3- The effect of treatment of ascites with paracentesis or diuretics needs evaluation to determine which is more effective in improving pulmonary function tests in cirrhotic patients.

4- We recommend further studies with DLCO

\section{REFERENCES}


1. Pugh RN, Murray-Lyon IM, Dawson JL et al. (1993): Transection of the esophagus for bleeding esophageal varices. Br J Surg., 60 (8): 646-9.

2. David TP, Michael BF (2006): The Hepatopulmonary syndrome. J. Hepatol., 4: 5617-5625.

3. Miller MR, Crapo R, Hankinson J et al. (2005): General considerations for lung function testing. Eur Respir J., 26 (1):153-61.

4. Vachiery F, Moreau R, Hadengue A et al. (1997): Hypoxemia in patients with cirrhosis: relationship with liver failure and hemodynamic alterations. J Hepatol., 27: 492-495.

5. Hourani J, Bellamy P, Tashkin D et al. (1991): Pulmonary dysfunction in advanced liver disease frequent occurrence of an abnormal diffusion capacity. Am J Med., 90: 693-700.

6. Yao EH, Kong BC, Hsue GL et al. (1987): Pulmonary function changes in cirrhosis of the liver. Am J Gastroenterol., 82:352-354.
7. Medha Y, Raghu J, Deshmukh S (2008): Arterial hypoxemia in patients with cirrhosis of liver. JAPI., 5: 681-684.

8. Konstantinos C, Dimitrios $P$, Leonidas $Z$ et al. (2007): Alteration in arterial blood parameters with liver cirrhosis and ascites. Int J Med Sci., 4 (2): 94-97.

9. Irem P, Suleyman S, Melih K et al. (2008): The relationship between severity of liver cirrhosis and pulmonary function. Dig Dis Sici., 53: 1951-1956.

10. Chang SC, Shiao GM, Lee SD et al. (1997): Therapeutic effects of diuretic and paracentesis on lung function in patients with non-alcoholic cirrhosis and tense ascites. J Hepatol., 26: 833-8.

11. Nagral A, Kolhtkar VP, Bhatia SJ et al. (1998): Pulmonary function tests in cirrhotic and non-cirrhotic portal hypertension. Indian J Gastroenterology, 12 (2): 36-40.

12. Djordje C, Mirjana P, Predrag R et al. (2002): Ventilatoryperfusion disorders in liver cirrhosis. Arch Gastroenterohepatol., 21: 3-4. 